ISSN: 0210-7287

DOI: https://doi.org/10.14201/16162021111731

\title{
CARMEN Y EL COLOR LOCAL DE ESPAÑA: ORIENTALISMO, GITANOS Y BAILES
}

\section{Carmen and the Local Color of Spain: Orientalism, Gypsies and Dances}

\author{
Rocío PlazA ORELLANA \\ Universidad de Sevilla \\ rplaza@us.es
}

Recibido: 09/09/2019; Aceptado: 12/02/2020; Publicado: 31/12/2021

Ref. Bibl. ROCÍO PLAZA ORELLANA. CARMEN Y EL COLOR LOCAL DE ESPAÑA: ORIENTALISMO, GITANOS Y BAILES. 1616: Anuario de Literatura Comparada, 11 (2021), 17-31

RESUMEN: En este artículo analizamos la evolución de tres rasgos escénicos de la ópera Carmen de Bizet: el orientalismo, los gitanos y el baile español. Las acotaciones del libreto y la escenografía de sus primeras representaciones son el resultado de la evolución de aspectos que comenzaron a desarrollarse en las principales escenas parisinas a partir de 1820. Los decorados y la indumentaria se convirtieron en los recursos plásticos que crearon el color local español en la escena parisina. Unos elementos escénicos que se pusieron al servicio del ballet a principios del siglo XIX y que tendrían su difusión en la literatura de viajes a partir de 1840.

Palabras clave: Carmen; Georges Bizet; Prosper Mérimée; baile español; ballet; Théophile Gautier.

ABSTRACT: In this article we analyze the evolution of three scenic features of the opera Carmen de Bizet: Orientalism, Gypsies and Spanish dance. The 
libretto and the scenography of its first performances are the result of the evolution of aspects that began to develop in the main Parisian scenes from 1820. Scenic design and costume became the plastic resource that created the local Spanish color in the Parisian scene. Some scenic elements appeared at the service of ballet in the early nineteenth century. These elements will be disseminated from 1840.

Key words: Carmen; Georges Bizet; Prosper Mérimée; Spanish Dance; Ballet; Théophile Gautier.

La escenografía y la indumentaria constituyen los principales recursos para la creación de la ambientación escénica de esta obra. Forman parte del acervo cultural con el que Francia diseñó a España en el siglo XIX. Una imagen escénica que comenzó a forjarse en la escena francesa a principios del siglo XIX en el ballet, a través de libretos inspirados en episodios de la historia española, y que tendría su proyección posterior con la eclosión de la literatura de viajes que comenzó a consolidarse en los últimos años de la década de 1840. A lo largo de esta década Prosper Mérimée escribió Carmen, que se publicó por primera vez en París en La Revue des Deux Mondes en 1845, que se completaría con dos capítulos en 1847. Treinta años después, concretamente en 1875, también en París se estrenaría la ópera de Georges Bizet. Ambas dispusieron de una recepción tibia por parte de sus lectores, espectadores y críticos, que, no obstante, se tornarían en un éxito posterior.

Los paisajes que constituyen los escenarios por los que transcurre la ópera de Bizet forman parte de imágenes consolidadas dentro del repertorio con el que la escena parisina concibió las historias españolas desde 1820. En estos años, el diseño de estas primeras propuestas escenográficas se creó para la danza, y son, por ello, el resultado de un proceso evolutivo que se concibió a partir de los espectáculos coreográficos. La danza, en conjunción con la literatura editada sobre España desde comienzos del siglo XIX, especialmente vinculada a la literatura de viajes, se convierten en los referentes que nutren los códigos plásticos que identifican el espacio y el ambiente español desde sus inicios en la escena francesa decimonónica.

Los paisajes y la caracterización de Carmen se convierten en imágenes escénicas creadas desde comienzos del siglo XIX en París a partir de la literatura escrita sobre España, con puntuales influencias españolas que analizaremos a lo largo de este estudio. El conocimiento de las escenografías originales y de los diseños de vestuario del estreno de la ópera de Bizet el 3 de marzo de 1875 en la Opéra Comique resulta insatisfactorio debido a la carencia de fuentes. Las descripciones que publicaron los periódicos 
vinculadas con su estreno resultan insuficientes. Particularidad que se suma al desconocimiento que disponemos en la actualidad tanto del creador de las escenografías como de los diseños de las imágenes originales, ya que solo se conocen los nombres de los diseñadores del vestuario de Carmen y de los dragones, Clairin y Detaille, respectivamente (Baker 1990, 230-242). Por estos motivos realizaremos un estudio sobre el núcleo de influencias y creaciones que marcaron las primeras imágenes. Para ello contamos como referencias visuales con los diseños de Émile Bertin sobre los actos I y IV de Carmen, elaborados posteriormente al estreno, y publicados por Hellmut Christian Wolff en 1968 (Wolff 1968); los diseños escénicos conservados en el Archivo Choudens de París, estudiados por Evans Baker en 1990 (Baker 1990, 230-242); y la reproducción de las escenas de la ópera publicadas por L'Illustration parisina el 13 de marzo de 1875. En lo concerniente a la indumentaria de Carmen, nos basaremos principalmente en esta última litografía del periódico parisino y en las fotografías que tomó Nadar a Cellestine Galli-Marié. Todas estas imágenes se analizarán en relación con las creadas con anterioridad dentro de la escena francesa, ya que, desde el origen del cuento de Carmen de Prosper Mérimée, las distorsiones que se producen a partir de su realidad se hacen en favor de personajes escénicos previamente diseñados, tanto en su descripción literaria como en su posterior traslación escénica, por Henry Meilhac y Ludovic Halévy.

Según Jean Sentaurens, Mérimée escribió a la condesa de Montijo unos meses antes de la publicación de su novela Carmen para contarle que había pasado ocho días encerrado para escribir una historia de una anécdota que ella le había contado hacía alrededor de quince años: «Se trataba de un jaque de Málaga que mató a su amante, la cual se dedicaba únicamente al público» (Sentaurens 2005, 2). Si, como asegura el investigador, esta noticia es el germen sobre el que florece la novela de Mérimée, y posteriormente el caudal del que se alimentará la ópera de Bizet, es necesario destacar la relevancia de las imágenes que se construyeron entre la escena parisina y la literatura francesa de viajes sobre España que desembocarán en la ópera; ya que el proceso de recreación de la ambientación de aire español, presente en la obra de Mérimée, es deudor de los contenidos concebidos sobre lo español desde la guerra de la Independencia hasta su publicación en 1845. A partir de este momento continuará su curso evolucionando con la imagen que ofrecerán la escena y la literatura hasta desembocar en 1875.

De este modo, la ambientación ideada por Meilhac y Halévy es el resultado de la imagen que sobre ella creó la cultura burguesa de Napoleón III y Eugenia de Montijo, hija de quien partió la anécdota que daría forma a la novela de Mérimée, según Sentaurens. No obstante, resulta relevante señalar que, al tratarse de un proceso de construcción prolongado en el 
tiempo, y fruto de los intereses, inclinaciones, modas y estéticas propias de la burguesía parisina, evolucionó con ella. Y lo haría precisamente en el marco temporal que media entre los últimos años del gobierno de Fernando VII, 1830, hasta 1875. Para ello se alimentó de todos los productos de consumo que fue capaz de crear la burguesía parisina para la diversión, la cultura y las modas a lo largo de estos años.

Existen tres características que perviven con protagonismo, tanto en la obra literaria de Mérimée como en la escénica de Bizet, con la misma intensidad con la que se crearon, a pesar del paso del tiempo: el orientalismo, los gitanos y el baile. Estos ya habían alcanzado una imagen codificada previa a la creación del paisaje que Mérimée le confeccionó a Carmen. Estos códigos previos influirán en la obra, e impregnarán el imaginario de los diseñadores escénicos que darían color, líneas y formas al universo creado musicalmente por Bizet. Los tres comenzaron prácticamente juntos su andadura con la conformación del ballet en la Academia Real de Música parisina al iniciarse la década de 1830. Los tres desembocaron en Carmen, y continuaron su curso a lo largo del siglo conformando nuevas imágenes. Los tres proceden de la selección e interpretación de la historia de España que utilizó la escena, ya que se convirtió en el primer recurso para la construcción de su imagen. Sería a partir de 1820 cuando comenzó a modelarse una imagen escénica para la danza que se identificaría con España, y de la que se servirían las producciones operísticas, dramáticas y coreográficas posteriores. Se gestaría dentro de la Ópera de París y en el ballet. Antes de estos años, la identificación de España se reducía básicamente a apariciones esporádicas en pasos concretos de baile, procedentes de la escuela bolera, fruto del conocimiento de las danzas españolas de maestros como Auguste Vestris y Charles Le Picq. Sin embargo, en el otoño de 1820 estos bailes ocasionales encontrarían un espacio de proyección en el ballet de Jean Aumer Les pages du duc de Vêndome, por la ambientación que ofreció en los divertissements. La historia transcurría en España, donde se encontraba luchando el duque de Vendôme.

Durante estos años la escena parisina fue ofreciendo piezas de temática española que recurrían a diferentes aspectos de la historia española, que se fueron acompañando de un requisito imprescindible que se incorporó para arropar las coreografías: el color local. Desde 1820 se sucedieron las producciones con referencias españolas en la escena, y que contaría en la Academia Real de Música parisina con el primer ballet ambientado en Sevilla. L'Orgie, un ballet en tres actos de Scribe y Jean Coralli con música de Caraffa, se estrenó el 18 de julio de 1831 (Scribe y Coralli 1831). Se trata de una obra ambientada en Sevilla y su campiña. Nos ofrece una de las primeras connotaciones que tendrán una correlación posterior con la creación 
de la ópera de Carmen, precisamente en el acto primero concebido como el interior de la sala de una fonda, llamada Soleil d'Or. Ubicada próxima a la ciudad se trata de un espacio donde comen y beben toda una serie de personajes pintorescos como soldados, monjes, campesinos, entre los cuales bailan fandangos unas jovencitas y unos muchachos mientras otras tocan las castañuelas:

SCÈNE PREMIÈRE. Plusieurs tables sont dressées dans l'hotellerie.

Des soldats, des moines, des paysans boivent et mangent ensemble à diferentes tables. Au milieu du théâtre, des jeunes filles et des garçons du pays dansent des fandangos, pendant que d'autres jouent des castagnettes. La signora Gaëtana, l'aubergiste, va et vient, et sert tout le monde. Elle gronde Johanna et Inésille, ses nièces, qui, au lieu de servir les pratiques, prennent part de temps en temps à la danse. Elle secoue par le bras Peblo, son premier garçon, qui veut toujours s'assesoir et se reposer; elle lui montre différentes tables où on appelle; elle se retourne et voit Inésille, qui, tenant un plat et un broc de vin qu'on attend, s'amuse à danser, au risque de tout verser; sa colère. Les danseurs l'entourent. Le fandango devient plus animé. On entend au dehors un bruit de chevaux; on s'arrête, et on écoute. (Scribe y Coralli 1831, 1-2)

Una escena en su planteamiento bastante próxima en su concepción a la que se diseñó en el segundo acto de Carmen, concretamente en la recreación de la taberna de Lilas Pastia, donde siguiendo la misma distribución de las mesas, a la derecha y a la izquierda de la escena, despejando el centro, se distribuyen dos gitanas bailando al son de dos gitanos que rasguean la guitarra, en un ambiente salpicado de soldados.

Las diferencias que median entre la concepción de este primer acto de L'Orgie, que fue diseñado en sus decorados por Ciceri, con respecto a la taberna de Lilas Pastia radican en la desaparición de los personajes religiosos, la aparición de gitanos españoles y soldados y el tipo de baile que se concibe. Hacia 1875 el interés por los personajes religiosos decae. Sin embargo, destaca la aparición de gitanos españoles y soldados en el escenario, muy escasos o casi inexistentes en las producciones escénicas previas a 1831. De igual forma, también varía la propia naturaleza de los bailes señalados en los libretos. Las diferencias estriban en el protagonismo de las parejas, al ser bailes propios de la escuela bolera de su tiempo que se trasladaron hasta París, frente al predominio del baile por una mujer sola, desarrollado 
y comercializado en Sevilla especialmente a partir de 1840. En L'Orgie se impone el baile de parejas masculino y femenino con un paso de la escuela bolera, el fandango, acorde con la difusión desarrollada del mismo por las memorias de viajeros desde el último cuarto del siglo XVIII; mientras en la ópera de Bizet nos encontramos a dos gitanas bailando sin especificar ningún paso concreto. Cuando se escribe la acotación de Carmen de la taberna de Lilas Pastia, se incorpora como color local un baile interpretado por gitanas, es decir, un baile femenino. Esto se debe a la gran difusión que adquieren los bailes de mujeres solas en París a partir de la cachucha de Fanny Elssler en 1836, y por la evolución de estos en ciudades como Sevilla y Madrid (Plaza Orellana 2013).

Junto con los bailes, otro de los elementos que caracterizó la plasmación estética de la ópera de Carmen desde su estreno fue su decoración de ambiente orientalista. Podemos apreciarla en algunos de los diseños más relevantes que se realizaron del acto IV, en el arco que da entrada a la plaza de toros de Sevilla, como el diseño de Émile Bertin, el de Auguste Lamy de Choudens, el de Auguste Lamy de L'Illustration, el del cartel de su estreno diseñado por Prudent Leray o el diseño de A. Bonamore para $I l$ Teatro Illustrato de Milán, publicado en su portada el 16 de diciembre de 1880. En todos estos diseños encontramos la plasmación de la acotación del acto, formada por una plaza de Sevilla, que cierra al fondo de la escena con la pared de un coso taurino, cuya entrada está cerrada por un toldo en un día de corrida. Todas ellas reflejan elementos provenientes de la arquitectura andalusí, bien en recreaciones tomadas originalmente de la Alhambra, el Alcázar sevillano o la mezquita-catedral de Córdoba. Esta último destaca concretamente en el diseño de Bertin. La presencia de la estética orientalista escénica con referencias andalusíes comienza su andadura en París a través del ballet, dentro de las grandes producciones de la Academia Real de Música.

Dos años después de L'Orgie llegó un ballet a la ópera parisina con referencias orientales de España, que se convertiría en un auténtico triunfo. El 4 de diciembre de 1833 se estrenó un ballet que alcanzaría gran relevancia, La revuelta en el serrallo, diseñado escenográficamente por Ciceri, junto a sus alumnos Léger, Feuchères y Despléchin. Posiblemente se trate del primer gran éxito de un ballet ambientado en España. Los decorados representan arquitecturas orientales que pretenden evocar la Granada de los nazaríes. Los bocetos que se conservan de algunos de los cuadros diseñados por Pierre Luc-Charles Ciceri, como es el caso del Patio de los Leones representado en el acto I, la sala de recepción también del acto I o los baños del acto II, ofrecen una imagen particular de la arquitectura nazarí, totalmente alejada de su impronta estética y de su predominio decorativo; 
en favor de extrañas estructuras de corte clásico, próximas a las escenografías italianas tradicionales, salpicadas de detalles más próximos a recreaciones de las antiguas culturas mesopotámica y egipcia.

De cualquier forma, en su trama irrumpem otros componentes que se introducirán como recurso del color español, y que alcanzaría a Carmen: la magia y la brujería. Ismael, interpretado por Joseph Mazilier, al volver a Granada tras vencer a los castellanos, descubre que su amada Zulima, Marie Taglioni, se ha convertido en la favorita del rey Mohammet. Con esta trama comienza un espectáculo en el que se cruzarán por las calles granadinas, las Alpujarras, la Alhambra y el Generalife una rebelión de esclavas, un amuleto mágico que propicia la aparición de armas a quien lo conjura, espíritus femeninos, cárceles y jardines encantados. El diseño del vestuario de este ballet fue obra de Paul Lormier, quien apenas tres años después crearía el traje que se consagró como el identificador de la bailarina española en la cultura occidental de su tiempo: el traje con el que Fanny Elssler bailó la cachucha en Le diable boiteux en 1836. Por ello, este ballet, a pesar de los profundos cambios que experimentaría la imagen oriental española en muy poco tiempo, incorporó a la antigua Granada andalusí con una historia de amores pasionales y caprichosos ensamblados con la brujería como recurso, y consagró al que sería uno de los principales creadores de la imagen de España: el figurinista Paul Lormier.

El protagonismo de Lormier llegaría tres años después, junto a su compañero en el taller de diseño de figurines, Henri Orschswiller. El 1 de junio de 1836 se estrenó en la Academia Real de Música el ballet Le diable boiteux, en tres actos, coreografiado por Jean Coralli, con libreto de Edmon Burat de Gurgy y Adolphe Nourrit y música de Casimir Gide. Los decorados los diseñó un amplio equipo de escenógrafos. En esta obra de pasión, brujería y encantamientos, ubicada en Madrid, se unirían como ingredientes del color local español Oriente y los bailes. En lo concerniente al decorado destacaría el que realizó Fécheures, siguiendo las acotaciones de Burat para el tercer cuadro del primer acto, concebido como «un parque con castillo morisco; árboles y flores [...]» (Coralli y Burat de Gurgy 1836). De este modo los elementos "orientales", definidos ya como "mauresque», impregnaban de nuevo el ambiente escénico que identificaba las historias de España. En el segundo acto se sumaría otro elemento fundamental: un baile llamado la cachucha. La interpretación que realizó la bailarina Fanny Elssler en la segunda escena del segundo acto, rodeada por telones y bastidores que simulaban la escena del Teatro de la Ópera de Madrid, se convirtió en un éxito de dimensiones internacionales.

La cachucha, interpretada por Fanny sin pareja, siguiendo la impronta natural de los bailes de jaleos que se documentan en Cádiz y Sevilla desde 
los primeros años del siglo xIX, se convirtió en un icono de la danza española (Tamvaco 2000). Sobre ella se volcarían todas las definiciones futuras de los bailes españoles a lo largo del tiempo, ya fueran pasos de la escuela bolera, bailes de jaleos mixtos o el propio flamenco a partir de 1880, girando en torno a un principio denominador: la sensualidad. Con los sofisticados y estilizados pasos coreografiados por Coralli, la cachucha de Elssler se convirtió en una pieza fundamental que identificó a los bailes españoles. Una identificación que se producía desde el exotismo, considerado como exponente de valores orientales (Meglin 1993, 73-96; Arkin 1994, 303-325).

A partir de 1836, debido al amplio espectro que generó el éxito de esta cachucha por los principales teatros europeos a lo largo de toda la década de 1840 , se produjo la inserción de lo español dentro de las modas parisinas, concebido en el baile desde una perspectiva femenina. Es decir, que, siguiendo la trayectoria que marcó el ballet con el predominio femenino en la danza, París incorporaría a partir de la década de 1840 bailes españoles interpretados por una mujer sola. De esta forma, los bailes de jaleos, como el de Jerez, que tanta difusión alcanzaron también en París en estos momentos, se impondrían sobre la escena, junto con el olé y el vito (Plaza Orellana 1999). Los bailes se convirtieron en un elemento imprescindible de ese "color local». Por ello fueron incorporados por Halévy y Meilhac en la ópera cuando especifican que bailan dos gitanas. De este modo, el baile y la estética orientalista se funden en valores como el exotismo o la sensualidad de la naturaleza que se les atribuye, que, a su vez, terminaría extendiéndose hacia la confección de la indumentaria. En la ópera de Bizet se aprecia la impronta oriental en los diseños para Zelia Trebelli en su primera representación en Nueva York en 1884, similar en su tocado al que se exhibió en el Teatro del Verme de Milán en 1888.

Los bailes españoles fueron estilizados por los coreógrafos de la escena parisina, y se complementaron con diseños de vestuario o escenografías acordes con la demanda del público al que atendían. Por ello el paso de las compañías de bailarines españoles por la Academia Real de Música y de otras escenas parisinas no siempre resultó satisfactorio en todos los aspectos demandados, por no corresponderse con los referentes confeccionados sobre ellos y no responder a las expectativas generadas. Cuando se producía un desajuste dentro de estas expectativas se generaban anécdotas que resultan muy ilustrativas para explicar este fenómeno, como es el caso de la que se produjo con la llegada de la compañía de Dolores Serral, Manuela Dubiñón, Francisco Font y Mariano Camprubí durante el mes de mayo de 1834. Los bailarines españoles, con un repertorio basado en la escuela bolera, protagonizaron algunas escenas que se consideraron inapropiadas para el público, por lo que Louis Gentil escribiría sobre su actuación: «El 
público encontraba que esta exhibición no era apropiada para las tablas de la Ópera, y bajo ningún pretexto se le pudo imponer, ni tan siquiera por un cuarto de hora este tipo de diversión. Cada cosa volvió a su sitio y los bromistas fueron despedidos» (Tamvaco 2000, 105).

Los produjeron se producían porque la recreación de los bailes con todos sus recursos escénicos realizados por los coreógrafos, figurinistas y escenógrafos se impuso mayoritariamente en el gusto del público parisino sobre la propia realidad del baile español. Es decir, la estilización de los pasos; la confección creada por los modistos en tejidos vaporosos, blancos o satinados, y las escenografías salpicadas de arquitecturas orientales se aplaudieron por encima de la imagen que los bailarines españoles realmente podían aportar.

De cualquier forma, más allá de las críticas, la indeterminación y la inverosimilitud convivieron con naturalidad e impunidad en la escenificación de temas escénicos españoles con todos sus componentes de color local a lo largo de las décadas hasta alcanzar las primeras representaciones de la ópera Carmen, como evidencian las acotaciones de su libreto. Primarían el aspecto español, los aires españoles, los ambientes españoles confeccionados por los artistas escénicos parisinos por encima de cualquier acercamiento verosímil a su realidad (Meglin 1994; Arkin 1994; Haitzinger 2009). "Les choses espagnoles» continuarían su curso, especialmente reforzadas por el éxito del paso de la cachucha estilizado para Le diable boiteux por los compositores y los coreógrafos de la Academia Real Parisina.

No obstante, la inverosimilitud crearía un interesante debate que tendría entre sus principales exponentes al escritor y periodista Théophile Gautier. Su obra periodística y literaria sobre España irrumpe precisamente a partir 1840, cuando cristalizaron algunos de los elementos que habían aparecido con anterioridad en las narrativas escénicas españolas. Para comprenderlo resulta fundamental analizar la labor desempeñada a través de sus críticas periodísticas en La Presse desde 1836; la narración de su viaje a España publicada en el mismo periódico entre mayo y octubre de 1840 y editado definitivamente en 1843 con el título Tra los Montes (Gautier 1843); y la conjunción de ambas dedicaciones y pasiones a partir de 1841, cuando se consolidó como crítico y conocedor de España y sus cosas, especialmente de sus bailes. Su labor resultará imprescindible por su doble vertiente como difusor de nuevas imágenes sobre el país a través de su exitoso libro de viajes y como constructor de la escena a partir de su labor como crítico y creador.

Antes de su Tra los Montes, los principales núcleos de información se encontraban algo dispersos debido a la antigüedad de sus publicaciones, e incluso se fundamentaban en exitosas traducciones de memorias del 
inglés. Entre ellos destacan tres libros para comprender la interpretación escénica del legado andalusí, los bailes y los gitanos: el Voyage pittoresque et historique de l'Espagne de 1806-1820 (Laborde 1806-1820) y el Itinéraire descriptif de l'Espagne et tableau élémentaire des différentes branches de l'administration et de l'industrie de ce royaume de 1808-1809 (Laborde 1808-1809), ambos de Alexandre Laborde; y la traducción del texto en inglés de Henri Swinburne Voyage de Henri Swinburne en Espagne en 1775 et 1776, de 1787 (Swinburne 1787).

El interés de Gautier por los bailes españoles tiene un punto de inflexión: su viaje a España de 1840. Previo a este, su conocimiento sobre ellos se correspondía exclusivamente con los bailes que ofrecía la escena parisina, destacando como ejemplo sus referencias al espectáculo de 1836 de Le diable boiteux (Gautier 1845). En este texto describe los bailes españoles desde el prisma estético que imponía la escena parisina (Plaza Orellana 2013). Su viaje por España, publicado en paralelo a su propia evolución en el folletín de La Presse desde mayo de 1840, desvela la profunda impresión que generó en el escritor el encuentro con la realidad escénica y coreográfica española por lo poco que se parecía a lo que de ella había aprendido en París. Plasma un sinfín de detalles para resaltar el enorme desenfoque existente entra la estilizada, elegante, luminosa y efectista colección de imágenes del entorno musical español que volcaban las escenas parisinas frente a la falta de esplendor de sus auténticos modelos hispánicos. Y a partir de este reconocimiento, que en principio le desagrada y finalmente le conmueve, se convertirá en el principal defensor en París de los espectáculos españoles genuinos, solicitando, según las circunstancias y los intereses, un mayor acercamiento a sus modelos originales en detrimento de su esplendor escénico y de su estilización (Plaza Orellana 2013).

Las aportaciones que Gautier lega para el conocimiento de la escena francesa a través de sus críticas, que nos ofrecen una información imprescindible para comprender la concepción escénica de la ópera de Bizet, son la caracterización de los gitanos y el desinterés por parte del público aristocrático y burgués mayoritario hacia los bailes españoles en su naturaleza original. Sobre este segundo aspecto critica el confinamiento de los auténticos bailes españoles en teatros menores de índole popular y salas de variedades. Para comprender este traslado desde la aristocrática escena de la Academia Real de Música hacia los teatros de arrabal es necesario señalar el periplo de la primera compañía que fue aplaudida en esta sala. La compañía de Dolores Serral, Mariano Camprubí, Manuela Dubiñón y Francisco Font fue contratada por la Academia Real de Música para amenizar los bailes de carnaval de 1834, y comenzaron sus actuaciones desde diciembre de 1833 (Steingress 2006), donde continuarían hasta mayo de 1834 (Plaza 
Orellana 2005). Tras la despedida comentada anteriormente por Louis Gentil, no volverían a esta escena ni ellos ni las bailarinas españolas más importantes de su tiempo (Plaza Orellana 2013). Quedarían relegadas a escenas populares que Gautier, recién llegado de España, consideraba totalmente inapropiadas para espectáculos de semejante calidad. Y así lo expresó en 1847: "PPor qué Dolores Serral, cuyos pasos obtienen tanto éxito entre las piernas de Fanny y de Noblet, no está en la Ópera, donde está destinado su lugar desde hace tiempo, así como el de Camprubí?» (Gautier 1858-1859, 41). Gautier explicaba a sus lectores desde La Presse y Le Moniteur el rechazo que generaba en las escenas de la alta sociedad lo genuino, viéndose relegado a espacios de ambiente popular, y sobre todo de menos recursos escénicos.

No solo manifestaría su desacuerdo con el desplazamiento de los bailes españoles realizados por ellos con sus elementos propios fuera de la principal escena francesa, sino también se expresaría contra la caracterización que se hacía sobre las tablas de los gitanos españoles. Con vehemencia se manifestó contra la representación de los gitanos españoles en escena tras su viaje. Los gitanos españoles no serían estimados como elementos atractivos para los espectáculos y las artes hasta la irrupción del romanticismo. Las memorias de viajes franceses del siglo XVIII sobre España, como las de Jean François Bourgoing o Alexandre Laborde en los últimos años del siglo XVIII y primeros del XIX, con su tercera edición de su Itinéraire descriptif (18271830), reflejan una imagen conflictiva de los gitanos españoles, en la que se acentuaban sus aspectos negativos, como su dedicación al robo o a la brujería, para manifestar su desarrollo a la sombra de la civilización (Bourgoing 1797). No fue realmente hasta la década de 1830 cuando se convirtieron en personajes escénicos con caracteres de protagonista, cuando fueron estimados por la irrupción de los valores románticos. Y cuando lo hicieron, a partir de ese momento, correrían la misma suerte que los bailes.

La imagen de las gitanas de España en la escena parisina careció de matices. Se convertirán en personajes femeninos para la danza, la comedia, el drama o el canto lírico construidos sobre unos rasgos que se definían por un inquebrantable sentido de la libertad, unas innegables dotes para la adivinación y la brujería y una ausencia de reconocimiento hacia las normas. Caracteres que las convertían en generadoras de conflictos escénicos que se desencadenaban a partir del robo o de la mentira principalmente. Cuando se dio a conocer en Francia la obra más singular escrita hasta entonces sobre los gitanos, The Zincali (1841), de Georges Borrow, en la reseña que escribiera Philarète Chasles en La Revue des Deux Mondes, a pesar de ofrecer una perspectiva matizada, no vaciló en llamarlos una "raza depravada", que animaba "los bailes lascivos de sus mujeres y de sus hijas» (Philarete 
1841, 467). Con parte de estos ingredientes se crearon en estos momentos la Esmeralda de Víctor Hugo en 1831, al que seguiría el drama lírico Le Gitano, en octubre de este mismo año en el Teatro Molière; el drama lírico en cuatro actos de Partonneauz y Fontmichel, El Gitano o La Voile rouge en el Teatro Marsella en marzo de 1834; La Gitana de Eugène Cabanel, junto al vaudeville en un acto de Saint Yves y Xavier Les Gitanos ou Une Nuit à Bearn; o el drama en tres actos de Albolze y Paul Fouché El Gitano ou villes en montagne, estrenado en el Gaité en octubre de 1836, como parte de una larga lista en la que se sucederían personajes femeninos estereotipados que no venían de ninguna parte, no tenían tierra, y bien podían ser francesas, prusianas, andaluzas o sicilianas de una forma meramente accidental.

Gautier nos ofrece importantes referencias sobre lo que acontecía con los gitanos en las diferentes escenas parisinas, destacando su interés o su más absoluto desagrado. En su crítica resulta fundamental establecer una división que viene marcada por su viaje a España en 1840. Antes de él, su interés por el aspecto que ofrecían las gitanas sobre la escena se centraba en elementos como los que referencia en su crónica de La Gitana de Desvergers y Laurencin, estrenada en el Gymnase en julio de 1839, en la que destaca que su protagonista, además de bailar una cachucha y echar las cartas: "cambia cuatro veces de ropa, y estos vestidos son de una elegancia única». Interés estético que se basaba en el brillo de sus colores y el estampado de sus tejidos.

En 1839 eclosionaría definitivamente la moda de las gitanas escénicas, que en los años consecutivos se mantendría con regularidad, acostumbrando al público francés a la caracterización que ellos mismos crearon. Gautier, a gusto con la representación de las gitanas escénicas que conoció previamente a su viaje a España, realizaría una crítica bastante significativa sobre el estreno de La Gitana en el Gymnase en julio de 1839. Su protagonista bailaría una cachucha, echaría las cartas y le resultaría bastante interesante, como afirmaría desde La Presse, por la variedad, riqueza y colorido de sus atuendos (Gautier 1858-1859).

Si bien esto ocurría un año antes de su viaje a España, tras su retorno de la Península, las gitanas de la escena parisina empezaron a resultarle insoportables; tanto las bailarinas francesas que se caracterizaban de españolas y gitanas como las españolas que retocaban su toilette a la francesa. En la obra Los diamantes de la Corona, estrenada en la Opéra Comique en marzo de 1841, aparecieron los primeros síntomas. Aquel texto escrito por Scribe y por el autor de La Gipsy, Saint Georges, provocó en Gautier esta primera impresión sobre la gitana Catarina:

¡En verdad, la Catarina es una extraña bohemia! Es rubia y blanca con los ojos azules aterciopelados, una sonrisa de viñeta inglesa; su vestido 
es el más encantador y el más coqueto del mundo: faldas de satén y de terciopelo, redecilla de oro y de púrpura, toquilla azul, brazaletes dobles, unidos por una cadena de oro. No somos nosotros los que nos quejamos de esto, aunque hayamos visto en Granada, en Sevilla y en otros lugares, auténticas gitanas que no se parecen por nada del mundo a madame Thillon. (Gautier 1858-1859, 105)

Y señalaría que aquellas gitanas que le impresionaron en Andalucía jamás entrarían en un teatro parisino, porque: «Qué silbidos no se oirían desde todos los rincones de la sala, si una gitana así vestida cantara canciones similares sobre la escena de la Opéra-Comique, con su auténtico aspecto!» (Gautier 1858-1859, 105). Y afirmaría: "iLa bohemia fantasiosa de los señores Scribe y Saint-Georges se prefiere mil veces a cualquier pobre chiquilla macilenta, salvaje, quemada por el sol, relatando versos barrocos, como debería ser la gitana auténtica de color local!». Y concluiría: "Por lo demás, la bohemia de la Opéra-Comique sabe su mundo y conoce los asuntos de la sala como la palma de su mano» (Gautier 1858-1859, 105).

Aunque los asuntos de la sala siguieron manejados por los profesionales del espectáculo, diseñando gitanos al gusto de los parisinos, Gautier con los años pasaría de la recomendación a la indignación, y de esta definitivamente a la indiferencia. En septiembre de 1843 se estrenó en el Ambigú Los bohemios de París. Su crítica en La Presse manifestó su indignación:

¿Cómo pueden ustedes llamar a esos ladrones, esos asesinos, a todos esos malvados horribles, bohemios? Ustedes aplican ese nombre a esos espantajos que se retuercen en los fangos de París. Los hemos visto por docenas y no podemos asegurarle que se parezcan a los suyos. Si ustedes hubieran deambulado por el Albaycin de Granada, y hubiesen seguido el camino blanco de polvo que lleva hasta el monte Sagrado, se habrían encontrado con grandísimos pillos con el semblante altivo y nervioso, salvajes como los cigarros de La Habana, portando majestuosamente algún harapo sobre su espalda bronceada. Descamps los siguió, con el lápiz en la mano, con una respetuosa admiración. (Gautier 1858-1859, 105)

De esta forma, apenas dos años antes que Mérimée perfilara a Carmen, Théophile Gautier afirmaba que en un teatro como la Opéra Comique nunca podría aparecer una auténtica gitana española, ya que no encajaba con el canon que se había creado en París; como de igual modo tampoco eran capaces de plasmar la elegancia que les confería su sentido absoluto de la libertad, cuando destacaban su miseria desaliñándolas.

En los años siguientes no faltaría un espectáculo en París sin gitanos en ningún teatro de boulevard. Mérimée publicaría su retrato particular, y las bailarinas españolas continuarían llegando para ocupar esporádicamente 
las escenas del Variétes o del Gymnase. A partir de 1850 llegarían bailarinas como las sevillanas Petra Cámara y su hermana Ana, que se introducirían en el núcleo de confianza de Alejandro Dumas (Plaza Orellana 2013); la sevillana Manuela Perea (Plaza Orellana 2013; Steingress 2006); la gaditana Josefa Vargas, con su incorporación al baile español de una chaquetilla corta (Plaza Orellana 2013) que en su patrón llegaría hasta el figurín que estrenarían en la Opéra Comique Marie Galli en su Carmen de 1875 o Emma Calvé en 1892; los figurines de Ricard Moragas de 1888 o de Lluis Labarta del mismo año, que también servirían de inspiración para el diseño del figurín de Christian Lacroix para la ópera; o la malagueña Pepita Oliva, con su caracterización de gitana más próxima a los recuerdos que Gautier pretendía imponer al bailar.

Estas bailarinas andaluzas traerían hasta París los nuevos y viejos bailes de mujeres solas que se exhibían en los teatros, salones de academias y hoteles y otros lugares privados de Sevilla y Madrid para el consumo turístico y local. Bailes como el olé o el vito a lo largo de la década de 1840. El vito tendría la característica de bailarse sobre la mesa en una de sus modalidades, tal y como lo describirían Alejandro Dumas a sus lectores en 1847 y Charles Davillier en 1874; imagen que apreciamos en el dibujo sobre el acto II de Carmen, "La taberna de Lilas Pastia", de Choudens o en L'Illustration de Auguste Lamy. De igual forma, a finales de esta década y a lo largo de 1850, los maestros de bailes de Sevilla crearían coreografías que incorporaron al baile prendas como las mantillas sobre el pelo, y que encontrarían su exhibición en París, tanto en los pasos inventados de Lola Montes como en los de Petra Cámara o Manuela Perea en estos años (Plaza Orellana 2013; Steingress 2006). Aportaciones que también encontramos en las primeras representaciones de la ópera de Carmen, como vemos en los dibujos de L'Illustration de Lamy y también de Choudens del acto II, o en el diseño de Célestine Galli-Marié.

De esta forma, la plástica creada para la ambientación española con la que se arroparon los pasajes vitales de Carmen en su configuración inicial, así como su atuendo de gitana y bailarina, llegaron hasta bien entrado el siglo XX.

\section{BIBLIOGRAFÍA}

ARKIN, Lisa. "The Context of Exotism in Fanny Elssler's Cachucha». Dance Chronicle, 1994, 3, pp. 303-325.

BAKer, Evans. "The Scene Designs for the First Performances of Bizet's Carmen". 19th Century-Music, 1990, 13.3, pp. 230-242. 
Bourgoing, Jean François. Tableau de l'Espagne moderne. Paris: G. Dufour, 1797. CHASLes, Philarete. "Les Gypsies". Revue des Deux Mondes, 1841, XXVII, pp. 467-468. Coraldi, Jean y Edmon Burat De GuRgy. Le diable boiteux, ballet pantomime en trois actes. Paris: Roullet, 1836.

Gautier, Théophile. Tra los Montes. Paris: V. Magen, 1843.

Gautier, Théophile. "Le diable boiteux". En GaUTier, Théophile, Jules Janin y Philarete Chasles. Les beautés de l'Opéra ou chefs oeuvre lyriques. Paris: Soulié, 1845, pp. $1-7$.

Gautier, Théophile. Histoire de l'art dramatique en France depuis vingt-cinq ans. Paris: Hetzel, 1858-1859.

Guest, Ivor. «Théophile Gautier on Spanish Dancing». Dance Chronicle, 1987, 1, vol. 10, pp. 1-104.

Haitzinger, Nicole. "Female Bodies as the other Alterity on Stage». En Jeschke, Claudia, Nicole Haitzinger y Gabi VetTERman. Les Choses Espagnoles: Research into the Hispanomania of 19th Century Dance. München: Epodium Verlag, 2009, pp. 80-99.

LABORDE, Alexandre. Voyage pittoresque et historique de l'Espagne. Paris: Pierre Didot, 1806-1820.

LABORDE, Alexandre. Itinéraraire descriptif de l'Espagne et tableau élémentaire des différentes branches de l'administration et de l'industrie de ce royaume. Paris: H. N. Nicolle, 1808-1809.

Meglin, Joellen. "Fanny Elssler's Cachucha and Women's Lives: Domesticity and Sexuality in France in the 1830s». En Proceedings- Dance Reconstructed: Modern Dance Art Past, Present, and Future. New Brunswick: Rutgers University Press, 1993, pp. 73-96.

Plaza Orellana, Rocío. El flamenco y los románticos. Un viaje entre el mito y la realidad. Sevilla: Bienal de Flamenco, 1999.

Plaza Orellana, Rocío. Los bailes españoles en Europa. El espectáculo de los bailes de España en Europa. Córdoba: Almuzara, 2013.

SCriBe, Eugène y Jean Coralli. L'Orgie. Paris: Bezou Libraire, 1831.

Sentaurens, Jean. "La España de Mérimée les sienta demasiado bien a los españoles. El fabuloso destino del "cuentecillo gracioso" de la Señora de Montijo". En Bruña Cuevas, Manuel. La Cultura del otro: español en Francia, francés en España. Sevilla: Universidad de Sevilla, 2005, pp. 1-14.

STEINGRESS, Gerhard. ... Y Carmen se fue a París. Un estudio sobre la construcción artística del género flamenco (1833-1865). Córdoba: Almuzara, 2006.

Swinburne, Henri. Voyage de Henri Swinburne en Espagne en 1775 et 1776. Paris: Didot, 1787.

Tamvaco, J. L. Les cancans de l'Opéra. Le journal d'une habilleuse 1836-1848. Paris: CNRS, 2000.

Wolff, Helmut Christian. Oper: Szene und Darstellung von 1600 bis 1900. Leipzig: VEB Deutscher Verlag für Musik, 1968. 
